\title{
INFLUÊNCIA DA SANIFICAÇÃO SOBRE A QUALIDADE DE MELÃO 'AMARELO' MINIMAMENTE PROCESSADO: PARTE II
}

\author{
Influence of the sanitation on the quality of the fresh cut yellow melon: part II
}

\author{
Helga Parra dos Santos ${ }^{1}$, Roberta Hilsdorf Piccoli do Valle ${ }^{2}$
}

\begin{abstract}
RESUMO
Visando o melhor aproveitamento, a agregação de valor e a conveniência para o consumo, está sendo empregado o processamento mínimo do melão, colocando no mercado um produto in natura fresco pronto para o consumo. Objetivou-se com esta pesquisa avaliar a qualidade sensorial de melão 'Amarelo' minimamente processado sanificado com peróxido de hidrogênio $\left(\mathrm{H}_{2} \mathrm{O}_{2}\right)$ e dicloro isocianurato de sódio ( $\mathrm{NaDCC}$ ), armazenado a $4 \pm 1^{\circ} \mathrm{C}$ durante 16 dias. Foram realizadas análises de sabor, textura, aparência e cor. Ocorreu redução linear nos valores das notas de sabor e textura ao longo do período de armazenamento. As notas variaram entre 8 (muito boa) e 7 (moderadamente boa) nos períodos iniciais, reduzindo para 6 (ligeiramente boa) e 5 (indiferente) ao final do período de armazenamento, não caracterizando a rejeição destes parâmetros por parte dos provadores. $\mathrm{O}$ tratamento com $\mathrm{H}_{2} \mathrm{O}_{2}$ a $2 \%$ teve menor aceitação quanto ao sabor e textura. A aparência e a cor não foram influenciadas pelos tratamentos, mas receberam notas menores ao longo do período de armazenamento. Os valores das notas para aparência e cor se mantiveram em 8 (muito boa) até o penúltimo dia, recebendo nota 6 (ligeiramente boa) apenas no último dia de armazenamento. De acordo com os resultados obtidos, concluiu-se que o melão 'Amarelo' minimamente processado foi considerado de boa aceitação, não ocorrendo depreciação acentuada na qualidade sensorial. O tratamento com NaDCC 50 ppm obteve melhor aceitação quanto à sabor e textura do que o tratamento com $\mathrm{H}_{2} \mathrm{O}_{2}$ a $2 \%$.
\end{abstract}

Termos para indexação: Cucumis melo, sanificação, processamento mínimo, análise sensorial.

\begin{abstract}
The goal of this research was to evaluate the sensorial quality of fresh cut 'Yellow' melon, sanitized with hydrogen peroxide $\left(\mathrm{H}_{2} \mathrm{O}_{2}\right)$ and sodium dichloroisocyanurate $(\mathrm{NaDCC})$, stored at $4 \pm 1^{\circ} \mathrm{C}$ for 16 days. Flavor, texture, appearance and color analyses were performed. A linear reduction in the values of the scores of flavor and texture was abserverd along the storage period. The scores ranged between 8 (very good) and 6 (fair) in the early periods, falling down to 6 (slightly good) and 5 (indifferent) at the end of the storage period, not characterizing the rejection of the fruit by the tasters. The $\mathrm{H}_{2} \mathrm{O}_{2} 2 \%$ treatment was the least accepted regarding flavor and texture. Both appearance and color were not influenced by the treatments, but were given poorer scores along the storage period. The values of the scores for treatment and color remained 8 (very good) untill two days before the end of de experiment, receiving score 6 (slightly good) only on the last storage day. According to the results obtained, the fresh cut 'Yellow' melon was regarded with good acceptability, with no appreciable depreciation in the sensorial quality. The NaDCC $50 \mathrm{ppm}$ treatment gave better acceptance for flavor and texture in comparing with $\mathrm{H}_{2} \mathrm{O}_{2} 2 \%$.
\end{abstract}

Index terms: Cucumis melo, sanitation, minimum processing, sensorial analysis.

\section{(Recebido para publicação em 03 de outubro de 2003 e aprovado em 13 de abril de 2005)}

\section{INTRODUÇÃO}

Visando o melhor aproveitamento, a agregação de valor e a conveniência para o consumo, está sendo empregado o processamento mínimo do melão, colocando no mercado um produto in natura fresco pronto para o consumo.

Os produtos minimamente processados são aqueles submetidos à operações de limpeza, lavagem, seleção, descascamento, corte ou fatiamento, sanificação, embalagem e armazenamento, mas que apresentam qualidade semelhante à do produto fresco (CHITARRA, 2000). A chave para o sucesso nas vendas desses produtos será a oferta constante de produtos uniformes de alta qualidade. A baixa qualidade poderá afetar a confiança dos consumidores já conquistados e diminuir o crescimento do mercado (DURIGAN, 2000).

A utilização da análise sensorial no estudo dos produtos minimamente processados tem sido bastante aplicada e recomendada, uma vez que pode contribuir na descrição dos referidos produtos, estabelecer sua vida útil e mostrar de que forma os tratamentos aplicados refletem sobre a qualidade sensorial.

A qualidade sensorial para os produtos minimamente processados se refere, entre outros aspectos, à uma aparência e cor aceitáveis e atrativos, que despertem

\footnotetext{
1 Bióloga, Mestre em Ciência dos Alimentos, Departamento de Ciência dos Alimentos /DCA - Universidade Federal de Lavras/UFLA - Lavras, MG.
}

2 Engenheira de Alimentos, Professora Dr. em Ciência dos Alimentos /DCA -UFLA - Cx. P. 3037 - 37.200-000 - Lavras, MG. 
a atenção do consumidor levando-o a escolher este produto. Uma vez escolhido, o produto ao ser consumido, deve ter sabor e textura agradáveis, que se aproximem o máximo ao do produto fresco.

De acordo com Watada et al. (1990), a maturidade é importante atributo de qualidade em frutas minimamente processadas, pois frutas imaturas carecem de boa qualidade sensorial e as muito amadurecidas têm menor vida de prateleira. A seleção de variedades que apresentem amadurecimento mais lento, melhor retenção de textura ou melhor característica de sabor contribui para a extensão da vida de prateleira (CHITARRA, 2000).

A sanificação dos produtos minimamente processados tem importante papel na diminuição da deterioração, na manutenção da qualidade e no aumento da vida de prateleira. A escolha e aplicação do sanificante químico adequado ao produto minimamente processado são fundamentais para a indústria de alimentos. Deve ser utilizado aquele sanificante que não afete negativamente as características sensoriais e que ao mesmo tempo garanta a segurança microbiológica do produto (SAPERS \& SIMMONS, 1998).

O dicloro isocianurato de sódio $(\mathrm{NaDCC})$ é um composto clorado orgânico comercializado na forma de pó ou comprimido efervescente. Por atender a um processo de fabricação específico para uso em alimentos, não libera metais pesados e Trihalometano (compostos carcinogênicos) quando hidrolisado. Assim, a substituição dos compostos clorados inorgânicos, como o hipoclorito de sódio, pelo NaDCC para uso em alimentos já está consolidada desde a década de 90 nos EUA e Europa (MACEDO, 2001).

O peróxido de peróxido de hidrogênio $\left(\mathrm{H}_{2} \mathrm{O}_{2}\right)$ é um forte oxidante devido à liberação do oxigênio, sendo usado como agente bactericida e esporicida. A Food and Drug Administration (FDA) aprova $\mathrm{O}_{2} \mathrm{H}_{2} \mathrm{O}_{2}$ para uso em alimentos. $\mathrm{Na}$ indústria de alimentos é aplicado na esterilização de embalagens, na sanificação de equipamentos e utensílios e na pasteurização de leite (SAPERS \& SIMMONS, 1998).

Com este trabalho objetivou-se avaliar a influência da sanificação usando dicloro isocianurato de sódio 50 ppm e peróxido de hidrogênio a $2 \%$ sobre as características sensoriais do melão 'Amarelo' minimamente processado durante o período de 16 (dezesseis) dias de armazenamento.

Os critérios estabelecidos para a escolha dos agentes sanificantes utilizados neste trabalho foram a facilidade de manuseio, disponibilidade no mercado, manutenção das qualidades sensoriais e segurança microbiológica visando sua aplicação prática em indústria de alimentos minimamente processados.

\section{MATERIAL E MÉTODOS}

O trabalho foi desenvolvido nos laboratórios de Fisiologia Pós-Colheita de Frutos e Hortaliças e de Análise Sensorial do Departamento de Ciência dos Alimentos da Universidade Federal de Lavras.

Melões 'Amarelo' (Cucumis melo var. inodorus) provenientes do Rio Grande do Norte foram adquiridos no comércio de Lavras-MG e selecionados quanto à ausência de danos mecânicos. Para limpeza superficial dos frutos usou-se detergente comercial e água. Os frutos limpos foram mergulhados em solução de $\mathrm{H}_{2} \mathrm{O}_{2}$ a $5 \%$ a $50^{\circ} \mathrm{C}$ por 15 minutos. Logo após, estes foram descascados, retiradas as sementes, cortados em cubos de aproximadamente $2 \mathrm{~cm}$ de comprimento e mergulhados por 3 minutos em soluções de NaDCC a $50 \mathrm{ppm}$ (na forma de comprimido efervescente), $\mathrm{H}_{2} \mathrm{O}_{2}$ a $2 \%$ e água destilada (controle). Para retirada do excesso de água após o banho nas soluções de tratamento, os cubos de melão foram drenados por aproximadamente 1 minuto em tecido de organza estéril. Após, os frutos foram acondicionados em embalagens de polietileno e armazenados a $4 \pm 1^{\circ} \mathrm{C}$ e $98 \%$ de UR, por um período de 16 dias. As análises realizadas foram: sabor, textura, aparência e cor.

O painel sensorial foi composto de nove provadores, de ambos os sexos, que avaliaram amostras de melões minimamente processados dos tratamentos controle, $\mathrm{NaDCC} 50 \mathrm{ppm}, \mathrm{H}_{2} \mathrm{O}_{2}$ a $2 \%$ e amostras de melões em estado fresco cortados na hora da prova. Foram utilizadas duas fichas: uma para prova de sabor e textura e outra para aparência e cor. Para atribuição de notas foi utilizada uma escala hedônica de 9 pontos em que: $9=$ extremamente boa; $8=$ muito boa; $7=$ moderadamente boa; $6=$ ligeiramente boa; $5=$ indiferente; $4=$ ligeiramente ruim; $3=$ moderadamente ruim; $2=$ muito ruim e $1=$ extremamente ruim.

A textura e sabor foram avaliados em cabines individuais, com luz vermelha para mascarar a cor das amostras. Os provadores recebiam simultaneamente quatro amostras, em duplicata, colocadas em copos descartáveis codificados com números aleatórios de 3 dígitos.

$\mathrm{Na}$ avaliação de aparência e cor foi utilizada uma cabine especial, revestida de fórmica branca, com quatro lâmpadas fluorescentes de 40 watts. As amostras foram dispostas no interior da cabine sobre placas de petri codificadas com números aleatórios de 3 dígitos, para que o provador não fosse influenciado ou não identificasse os tratamentos. 
O experimento foi conduzido em Delineamento Inteiramente Casualizado (DIC). O número de repetições foi igual ao número de provadores, ou seja, nove repetições. Os tratamentos foram dispostos em fatorial $4 \mathrm{x}$ 8 , sendo os fatores tratamentos (controle, dicloro isocianurato de sódio a $50 \mathrm{ppm}$, peróxido de hidrogênio a $2 \%$ e melões em estado fresco) e tempos de armazenamento $\left(\mathrm{T}_{0}=0\right.$ dia, $\mathrm{T}_{2}=3$ dias, $\mathrm{T}_{3}=4$ dias, $\mathrm{T}_{6}=7$ dias, $\mathrm{T}_{8}=9$ dias, $\mathrm{T}_{10}=$ 11 dias, $\mathrm{T}_{13}=14$ dias, $\mathrm{T}_{15}=16$ dias).

A parcela experimental foi composta por uma embalagem com aproximadamente $100 \mathrm{~g}$ de melão minimamente processado. As análises estatísticas foram realizadas pelo pacote computacional SISVAR, versão 6.12 (FERREIRA, 1998). Foi utilizado o Teste de F com significância de $1 \%$ e $5 \%$ de probabilidade.

\section{RESULTADOS E DISCUSSÃO}

Houve efeito significativo dos tratamentos, do período de armazenamento e interação entre estes dois fatores $(\mathrm{p}<0,01)$ para a variável sabor. Ocorreu redução das notas para o sabor durante o período de armazenamento (Figura 1). As notas variaram entre 8 (muito boa) e 7 (moderadamente boa) até o tempo 3, caindo para 6 (ligeiramente boa) e 5 (indiferente) ao final do período de armazenamento.

Até o $6^{\circ}$ dia de armazenamento não houve diferença significativa entre os tratamentos. $\mathrm{O}$ tratamento $\mathrm{H}_{2} \mathrm{O}_{2}$ a $2 \%$ foi o menos aceito quanto ao sabor no $8^{\circ}, 10^{\circ}$ e $15^{\circ}$ dias. No tempo 10, o NaDCC 50 ppm obteve a mesma aceitação de sabor que o tratamento fresco. No tempo 15, os tratamentos menos aceitos foram $\mathrm{NaDCC} 50$ ppm e $\mathrm{H}_{2} \mathrm{O}_{2}$ a $2 \%$, sendo que o controle e o fresco não diferiram entre si.

Não houve indicação de sabor fermentado em nenhum dos tratamentos ao longo do período de armazenamento.

A análise de variância mostrou que houve efeito significativo dos tratamentos, do tempo de armazenamento e interação entre tratamento e tempo $(\mathrm{p}<0,01)$ para a variável textura. Não houve diferença significativa entre os tratamentos nos tempos 0, 2, 3, 6 e 13 (Figura 2). No tempo 8 e $10, \mathrm{o} \mathrm{H}_{2} \mathrm{O}_{2}$ a $2 \%$ foi o tratamento menos aceito quanto à textura. No tempo 15, os tratamentos NaDCC 50 ppm e $\mathrm{H}_{2} \mathrm{O}_{2}$ a $2 \%$ receberam menores notas para a textura, sendo os menos aceitos. Durante o período de armazenamento, as notas variaram entre 8 (muito boa), 7 (moderadamente boa), 6 (ligeiramente boa) e 5 (indiferente).

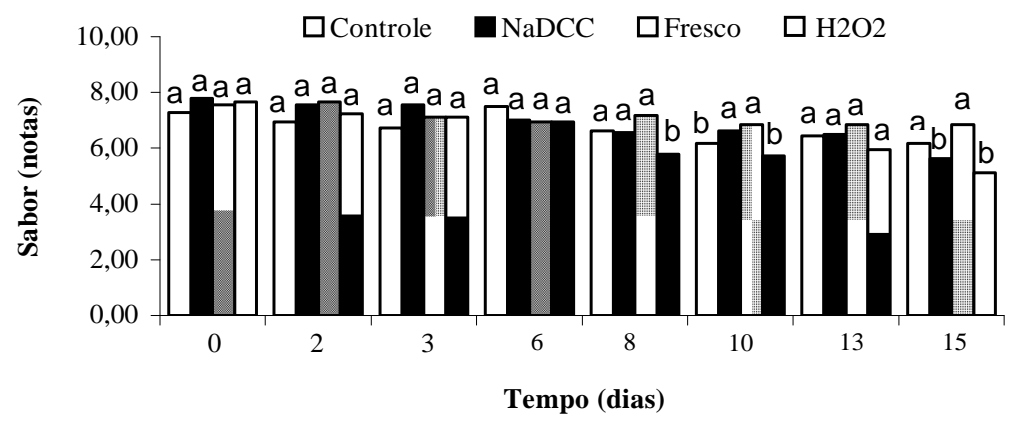

FIGURA 1 - Valores médios de notas para sabor de melão 'Amarelo' minimamente processado submetido a tratamentos com $\mathrm{NaDCC} 50 \mathrm{ppm}$ e $\mathrm{H}_{2} \mathrm{O}_{2}$ a $2 \%$, armazenado a $\pm 4^{\circ} \mathrm{C}$ por um período de 16 dias. Teste de $\mathrm{F}$ significativo a $1 \%$ e $5 \%$ de probabilidade.

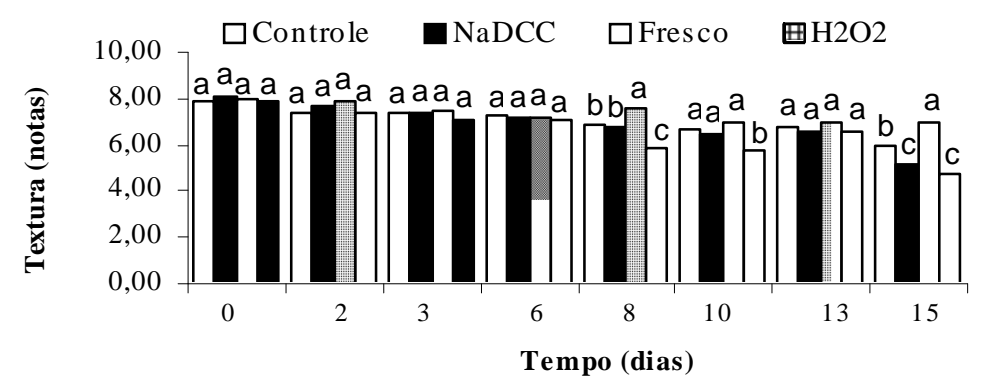

FIGURA 2 - Valores médios de notas para textura de melão 'Amarelo' minimamente processado submetido a tratamentos com $\mathrm{NaDCC} 50 \mathrm{ppm}$ e $\mathrm{H}_{2} \mathrm{O}_{2}$ a $2 \%$, armazenado a $\pm 4^{\circ} \mathrm{C}$ por um período de 16 dias. Teste de $\mathrm{F}$ significativo a $1 \%$ e $5 \%$ de probabilidade.

Ciênc. agrotec., Lavras, v. 29, n. 5, p. 1034-1038, set./out., 2005 
O peróxido de hidrogênio, apesar de não gerar subprodutos do processo de desinfecção por ser decomposto em água e oxigênio, tem forte poder de oxidação, atacando componentes celulares essenciais, tanto de microrganismos quanto das células vegetais. Dependendo da concentração usada, pode levar ao rompimento das células vegetais, com efeitos sobre a textura. A textura é um dos mais importantes atributos para a aceitação de um produto. Frutos e hortaliças perdem seu frescor, firmeza e textura típicos quando expostos ao armazenamento refrigerado até mesmo por curtos períodos. No processamento mínimo essas alterações são aceleradas devido ao descascamento e fatiamento (KADER, 2002).

Houve efeito significativo do período de armazenamento $(\mathrm{p}<0,01)$ sobre a variável aparência. Pela Figura 3 , observa-se a tendência de decréscimo linear nas notas atribuídas à aparência do melão minimamente processado. Mas, durante todo o período de armazenamento, as notas não foram inferiores a 6 (ligeiramente boa), mostrando a aceitação da aparência do produto por parte dos provadores. Não houve diferença estatisticamente significativa dos tratamentos em relação à aparência.

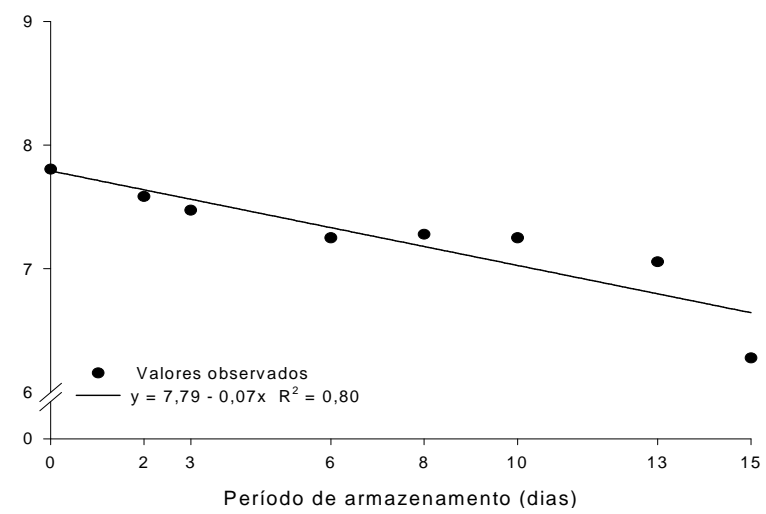

FIGURA 3 - Valores médios, equação de regressão e coeficiente de determinação de aparência em melão 'Amarelo' minimamente processado submetido a tratamentos com NaDCC 50 ppm e $\mathrm{H}_{2} \mathrm{O}_{2}$ a $2 \%$, armazenado $\mathrm{a} \pm 4^{\circ} \mathrm{C}$ por um período de 16 dias.

Houve efeito significativo do período de armazenamento $(p<0,01)$ para a variável cor. Na Figura 4 observa-se que as notas para a cor diminuíram de 8 (muito boa) para 6 (ligeiramente boa), ao final do período de armazenamento, não caracterizando rejeição da cor do melão minimamente processado por parte dos provadores. Os tratamentos não influenciaram estatisticamente a cor do produto.

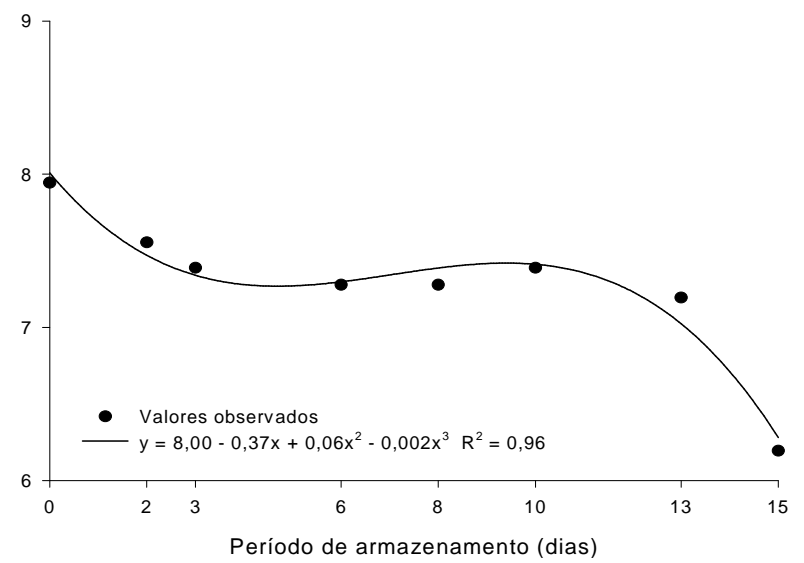

FIGURA 4 - Valores médios, equação de regressão e coeficiente de determinação de cor em melão 'Amarelo' minimamente processado submetido a tratamentos com NaDCC 50 ppm e $\mathrm{H}_{2} \mathrm{O}_{2}$ a $2 \%$, armazenado a $\pm 4^{\circ} \mathrm{C}$ por um período de 16 dias.

\section{CONCLUSÕES}

De acordo com os resultados obtidos, concluiu-se que o melão 'Amarelo' minimamente processado mantido nas condições deste experimento, foi considerado de boa aceitação, não ocorrendo depreciação acentuada na qualidade sensorial. O tratamento com NaDCC 50 ppm obteve melhor aceitação quanto ao sabor e textura do que o tratamento com $\mathrm{H}_{2} \mathrm{O}_{2}$ a $2 \%$, até os 16 dias após o processamento.

\section{REFERÊNCIAS BIBLIOGRÁFICAS}

CHITARRA, M. I. F. Processamento mínimo de frutos e hortaliças. Lavras: UFLA/FAEPE, 2000. 113 p.

DURIGAN, F. J. Processamento mínimo de frutas. In: ENCONTRO NACIONAL SOBRE PROCESSAMENTO MÍNIMO DE FRUTAS E HORTALIÇAS, 2., 2000, Viçosa. Palestras... Viçosa: UFV, 2000. p. 86-88.

FERREIRA, D. N. Sistema de análise estatística para dados balanceados. Lavras: UFLA/DEX/ SISVAR, 1998.

KADER, A. A. Postharvest biology and technology: an overview. In: __ -----Postharvest technology of horticultural crops. 3. ed. Davis: University of California, Agriculture and Natural Resources, 2002. 519 p. (Publication, 3311). 
MACEDO, J. A. B. Subprodutos do processo de desinfecção de água pelo uso de derivados clorados. Juiz de Fora: [s.n.], $2001.67 \mathrm{p}$.

SAPERS, G. M.; SIMMONS, G. F. Hydrogen peroxide disinfection of minimally processed fruits and vegetables. Food Technology, Chicago, v. 52, n. 2, p. 4852, Feb. 1998.

WATADA, A. E.; ABE, K.; YAMUCHI, N. Physiological activities of partially processed fruits and vegetables. Food Technology, Chicago, v. 50, p. 116-122, May 1990.

Ciênc. agrotec., Lavras, v. 29, n. 5, p. 1034-1038, set./out., 2005 